Best Pract Res Clin Rheumatol. 2010 April ; 24(2): 253-265. doi:10.1016/j.berh.2009.11.001.

\title{
Lumbar Spinal Stenosis
}

Stephane Genevay, MD $^{1}$ and Steven J Atlas, MD, MPH ${ }^{2}$

Stephane Genevay: stephane.genevay@hcuge.ch; Steven J Atlas: satlas@partners.org

${ }^{1}$ Division of Rheumatology, University Hospitals of Geneva, Switzerland, Tel: 00412238236 73, Fax: 0041223823535

${ }^{2}$ General Medicine Division, Massachusetts General Hospital, Boston MA, USA, Tel: 617-724-4736, Fax: 617-724-3544

\section{Abstract}

Lumbar spinal stenosis (LSS) is most commonly due to degenerative changes in older individuals. LSS is being more commonly diagnosed and may relate to better access to advanced imaging and to an aging population. This review focuses on radicular symptoms related to degenerative central and lateral stenosis and updates knowledge of LSS pathophysiology, diagnosis and management. Since patients with anatomic LSS can range from asymptomatic to severely disabled, the clinical diagnosis focuses on symptoms and examination findings associated with LSS. Imaging findings are helpful for patients with persistent, bothersome symptoms in whom invasive treatments are being considered. There is limited information from high quality studies about the relative benefits and harms of commonly used treatments. Interpreting and comparing results of available research is limited by a lack of consensus about the definition of LSS. Nevertheless, evidence supports decompressive laminectomy for patients with persistent and bothersome symptoms. Recommendations favor a shared decision making approach due to important trade-offs between alternative therapies and differences among patients in their preferences and values.

\section{Keywords}

Lumbar spinal stenosis; neurogenic claudication; foraminal stenosis; radicular pain

\section{Introduction}

Lumbar spinal stenosis (LSS) is commonly used to describe patients with symptoms related to anatomical reduction of the lumbar spinal size. The challenge to this anatomically based definition is that while necessary for the diagnosis of LSS, it is not sufficient to determine the severity of symptoms and functional impairment that leads a patient to seek treatment. Indeed, even severe anatomical spinal stenosis may be present in asymptomatic patients. This review focuses on the clinical management of degenerative LSS including the etiology and natural history, symptoms and physical findings, diagnostic testing, and treatment options.

Degenerative spinal stenosis can occur with other conditions including degenerative spondylolisthesis or degenerative scoliosis. Though many studies of degenerative LSS include individuals with these conditions, they are beyond the scope of this review.

Correspondence to: Steven J Atlas, sat lasepartners .org.

Publisher's Disclaimer: This is a PDF file of an unedited manuscript that has been accepted for publication. As a service to our customers we are providing this early version of the manuscript. The manuscript will undergo copyediting, typesetting, and review of the resulting proof before it is published in its final citable form. Please note that during the production process errors may be discovered which could affect the content, and all legal disclaimers that apply to the journal pertain. 
The first clinical description of LSS is attributed to Verbiest in 1954, (1) although earlier descriptions are available.(2) More than 50 years later, there is still no widely accepted diagnostic or classification criteria for the diagnosis of LSS and as a consequence studies use widely differing eligibility criteria that limit the generalizability of reported findings.(3) Among older individuals, LSS can be a highly disabling condition,(4) and is the most common reason for spinal surgery.(5,6) Though LSS is a growing concern with the aging of the population, few studies have examined how prevalence or incidence is changing.(5)

\section{Etiology and pathophysiology}

Spinal stenosis is most commonly classified as either primary, caused by congenital abnormalities or a disorder of postnatal development,(7) or secondary (acquired stenosis) resulting from degenerative changes or as consequences of local infection, trauma or surgery. The focus of this review is on the most common cause, a slowly progressive degenerative process that predominates at the three lower lumbar levels.(8) The natural history of spinal stenosis remains poorly understood with studies reporting about a half of patients remain clinically stable, with a quarter worsening or improving.(9) For any individual patient, the course can be unpredictable with flares and stable periods over time.(10)

Degenerative LSS anatomically can involve the central canal, lateral recess, foramina or any combination of these locations (Figure 1). Central canal stenosis may result from a decrease in the anteroposterior, transversal or combined diameter secondary to loss of disc height with or without bulging of the intervertebral disc, and hypertrophy of the facet joints and the ligamentum flavum. Fibrosis is the main cause of ligamentum flavum hypertrophy and is caused by accumulated of mechanical stress, especially along the dorsal aspect of the ligamentum flavum. Transforming growth factor (TGF)- $\beta$ released by the endothelial cells may stimulate fibrosis, especially during the early phase of hypertrophy.(11) The same processes, decreased disc height, facet joint hypertrophy (with or without spondylolisthesis) and/or vertebral endplate osteophytosis can also result in lateral recess stenosis. Foraminal stenosis can be either anteroposterior resulting from a combination of disc space narrowing and overgrowth of structures anterior to the facet joint capsule, and/or vertical resulting from posterolateral osteophytes from the vertebral endplates protruding into the foramen along with a laterally bulging annulus fibrosis or herniated disc that compresses the nerve root against the superior pedicle.(12) Foraminal stenosis more frequently involves the L5 nerve root, as the L5-S1 foramen is the one with the smaller foramen/root area ratio.(12)

In addition to these slowly progressive degenerative anatomical changes, lumbar spine stenosis has an important dynamic component. The available space in the central canal decreases in loading and extension and increases in axial distraction and flexion. (13) The same dynamics also affect the foramen with flexion causing a $12 \%$ increase, and extension a $15 \%$ decrease, in surface area.(14)

The most important physiopathological hypothesis for degenerative LSS is the two-level stenosis concept which was first proposed by Porter(15) based on animal studies(16) and clinical observations. Signs and symptoms are thought to result from vascular compromise to the vessels supplying the cauda equina (central stenosis) or from pressure on the nerve root complex (lateral stenosis) by the degenerative changes. Experimentally, it has been shown that moderate constriction induced pressure involving the cauda nerve roots will disturb their nutrition and further experimental studies have given support to this hypothesis.(17,18) The clinical impact of these changes is related to the speed by which the compression develops. $(16,19)$ There have been several hypothesized effects of the nerve root constriction: 1) A direct obstruction of the blood flow to the cauda equina;(20) 2) An intraosseous and cerebrospinal pressure change affected by posture;(21) and 3) a direct neuronal compression of the nerve 
roots.(22) The impact of postural changes on the central spinal canal were evaluated 15 years ago when Takahashi et al reported increased epidural pressure during extension, especially when standing.(23) Similar results were shown for foraminal pressure.(24) In addition, this study also demonstrated that in symptomatic patients with imaging showing central canal stenosis limited to one level without foraminal stenosis, foraminal pressure was still increased, suggesting that the two-level hypothesis may still apply to these patients. All these patients recovered from their leg symptoms after central decompression without foraminotomy.(24)

Despite rapidly increasing rates of corticosteroid spinal injections $(25,26)$, there is limited information on the role of local inflammatory mediators(27) in degenerative LSS. Higher levels of interleukin (IL)-1 $\beta$ but not of IL- 6 or tumor necrosis factor (TNF)- $\alpha$ have been found in cartilage and synovial membrane of zygapophysal joint in patients with LSS compared to patients with a disc herniation.(27) The authors postulated inflammatory cytokines spreading from the joint space into the ligamentum flavum and the spinal canal. A report of high cytokines levels in epidural fat of patients with LSS has not been confirmed. (Genevay et al. Spineweek; Geneva 2008, oral communication)

\section{Clinical symptoms and physical findings}

Despite a clinical definition that often relies on anatomic findings, the clinical diagnosis and the assessment of the severity of LSS depends primarily on the patient's description of their symptoms and on the physical examination. When interventions are being considered, correlation with imaging findings is also essential. Degenerative LSS is uncommon in patient younger than 50 years in contrast to those with primary LSS due to a congenitally narrowed canal.

The symptom most commonly attributed to LSS is neurogenic claudication, also referred to as pseudoclaudication. Neurogenic claudication refers to leg symptoms encompassing the buttock, groin, and anterior thigh, as well as radiation down the posterior part of the leg to the feet. In addition to pain, leg symptoms can include fatigue, heaviness, weakness and/or paresthesia. Patients with LSS also can report nocturnal leg cramps(28) and neurogenic bladder symptoms.(29) Symptoms can be unilateral or more commonly bilateral and symmetrical. Patient may suffer from accompanying back pain but leg pain and discomfort is usually more bothersome.

A key feature of neurogenic claudication is its relationship to the patient's posture where lumbar extension increases and flexion decreases pain. Symptoms progressively worsen when standing or walking and are relieved by sitting. Relief with sitting in LSS contrasts with most nonspecific low back pain which is commonly exacerbated by prolonged sitting. Patients with neurogenic claudication report that laying flat is often associated with less relief while lying on the side (permitting lumbar flexion) is more comfortable. The distance that can be walked before symptoms occur is more variable in those with neurogenic claudication compared with vascular claudication, and is increased by forward bending of the torso (increased thoracic kyphosis and decreased lumbar lordosis). As a consequence, patients adopt a position with hip and knee slightly flexed sometimes referred as "simian stance".(30) In contrast to those with vascular claudication, sitting but not standing will relieve symptoms, walking uphill will be better tolerated than downhill walking, and exercise on a stationary bicycle in a seated flexed position will be better tolerated than walking in the erect position.

Examination of the lower back will often reveal non-specific reduced mobility. Extension may be more limited than flexion.(31,32) Hamstring tightness is often described.(33) The neurologic examination typically is normal, and findings when present are usually mild motor weakness or sensory changes. Some of these signs may be increased immediately after the 
patient performs symptomatic exercises.(34) Absent or decreased ankle reflexes have been reported in about half of patients but this sign is frequently found in older patients.

In addition to neurogenic claudication, lumbar spinal stenosis can present with symptoms that are more radicular in nature. Unlike neurogenic claudication that is more commonly bilateral and associated with central canal stenosis, radicular symptoms due to spinal stenosis are more often unilateral and related to stenosis of the lateral recess or the foraminal canal. Patients tend to be younger (32) and often have pain at rest and at night which is increased by the Valsalva maneuver.(12) Leg pain is often described as severe and radicular in distribution, and may be exacerbated with lumbar extension to the painful side (Kemp's test).(12) Examination findings may include a limited lumbar range of motion especially in extension, focal motor weakness in a specific root distribution, variable straight-leg tension signs, and diminished subjective sensation and reflexes in specific root distributions.

Some patients may report symptoms that are difficult to definitively attribute to LSS. For example, they may only report low back pain (without leg symptoms), that are typical of neurogenic claudication (e.g. characteristic positional nature of symptoms).

The only study assessing the value of patient reported and physical findings in the diagnosis of LSS compared 43 patients, in whom clinicians had at least $80 \%$ confidence that symptoms were due to LSS with 32 in whom clinicians had less than $20 \%$ confidence that symptoms were due to LSS.(35) Variables associated with the diagnosis of LSS included older age, thigh pain with 30 seconds of lumbar extension, absence of pain while seated, and wide-based gait.

\section{Diagnosis tests}

\section{Questionnaires}

Standardized questionnaires can be used to identify and classify patients with symptoms and findings that may be due to LSS. Konno et al (36) evaluated a self-administrated diagnostic tool to identify patients with LSS and differentiate between those with radicular compression and neurogenic claudication (referred to as "cauda equina" symptoms in their manuscript) using symptom reports from 137 patients with LSS and 97 with lumbar disc herniation (DH) following successful surgical treatment. A prediction rule was then derived from 115 other patients with LSS (Table 1) and was further validated in a population of 250 patients with low back pain with or without leg pain. In a second study (37), the same investigators used a regression coefficient-based scoring system to develop a score-based prediction rule (Table 2) from a cohort of 469 patients (222 LSS, 83 lumbar DH, 111 non-specific back pain, 53 non back related diagnosis). The model had a good discriminative power, and a score equal or greater than 7 was found to have a sensitivity of $92.8 \%$ and a specificity of $72.0 \%$ for the diagnosis of symptomatic LSS.

\section{Radiological imaging studies}

Studies in asymptomatic populations have found that up to $20 \%$ of subjects had imaging findings consistent with spinal stenosis.(38) As a consequence correlating symptoms and physical exam findings with imaging results is necessary when making a definitive diagnosis is required, such as when considering invasive interventions. This is made more challenging because there are no universally accepted radiographic definitions for the diagnosis of central, lateral recess and foraminal stenosis. Most studies rely on criteria published by Verbiest et al. (39) He defined relative spinal stenosis as a diameter between 10 and $12 \mathrm{~mm}$ whereas absolute stenosis was a diameter less than $10 \mathrm{~mm}$. This method has been criticized for ignoring the trefoil shape of the LSS and the intrusion of ligamentum flavum and disc material in degenerative stenosis.(40) 
Schonstrom et al. showed that neurogenic claudication due to LSS was better defined by the cross-sectional area (CSA) of the dural sac, but that the CSA of the lumbar vertebral canal was unrelated to that of the dural sac.(41) From in vitro(42) and in situ (43) studies, the authors postulated that constrictions above the critical size 70 to $80 \mathrm{~mm} 2$ would be unlikely to cause symptoms and signs of cauda encroachment. Subsequently, conflicting results have been published concerning the relationship between symptom severity and dural CSA. Even after axial loading, no statistically significant correlations were found in some studies.(44) However, in another study, the use of the minimal CSA of the dural sac in central stenosis was found to be correlated with neurogenic claudication assessed measuring the maximum tolerated walking distance.(45) In a meta-analysis, CT and MRI were found to have similar accuracy for the assessment of central stenosis.(46)

\section{Electrodiagnostic studies}

Patients with symptoms, physical examination and imaging findings consistent with LSS do not require additional testing. Although there is little evidence in the literature, electrodiagnostic evaluation is used in some patients with symptoms and findings that are equivocal or conflicting with imaging results and in whom procedures are being considered. Electrodiagnostic criteria for stenosis have been proposed:(47) mini-paraspinal mapping with a one side score > 4 (sensitivity $30 \%$, specificity $100 \%$ ), fibrillation potential in limb muscles (sensibility $33 \%$, specificity $88 \%$ ), absence of tibial H-wave (sensitivity $36 \%$, specificity $92 \%$ ). Better sensitivity was found for a composite limb and paraspinal fibrillation score (sensitivity $48 \%$, specificity $88 \%$ ).

\section{Treatment options (Table 3)}

Despite a common perception that patients with LSS have invariably progressive symptoms, the natural history of patients treated non-surgically does not support this belief. $(48,49)$ According to a recent review from the North American Spine Society, the clinical course of mild or moderate symptomatic LSS patient can be favorable in 30 to 50\%, but less is known about the natural history of patients presenting with severe symptoms.(50)

\section{Conservative treatments}

Most patients with symptomatic LSS are tried on a variety of conservative treatments in spite of little evidence to guide their care. Much of the evidence for these treatments is extrapolated from studies of patients with non-specific low back pain or patients with radiculopathy due to a disc herniation. The need for better evidence from studies involving patients with LSS is recognized. $(50,51)$

\section{Medications}

Analgesics, NSAIDs, muscle relaxants and opioid are commonly used in patients with LSS although their use is extrapolated from studies of patients with non-specific low back pain. Each of these medication classes poses risks to patients, especially among older individuals. Other medications have been evaluated in patients with LSS. An old randomized cross-over trial of low methodological quality found a positive effect of intramuscular calcitonin(52), but two more recent studies using intranasal calcitonin could not replicate the findings. $(53,54)$ In patients with neurogenic claudication and imaging confirmed LSS, the addition of gabapentin to standard therapy (NSAIDs, physical therapy and steel bracing) was superior to placebo both in terms of pain sensory disturbances and walking distance.(55) In subgroup analysis the effect was mainly observed in patients with mild symptoms. Limaprost, an oral PGE1 derivative with known vasodilating effects, was shown superior to etodolac (NSAIDs), in term of quality of life (SF-36), the primary endpoint, but also in terms of walking distance and patients subjective 
improvement and satisfaction.(56) A trend toward less leg pain but no difference in back pain was observed in the limaprost group.

\section{Physical therapy, exercises and bracing}

A comprehensive rehabilitation program of manual therapy, stretching, and strengthening exercises for the lumbar spine and hip region have been advocated for those with LSS (5759). The importance of endurance exercises to retard the deleterious consequences of inactivity and deconditioning is also emphasized. However, few randomized studies have evaluated physical therapy in LSS. In one study, Whitman et al. reported perceived recovery (but not on pain or function) improved at 1 year of an intervention that included manual physical therapy, exercises to improve strength, mobility and coordination, and a progressive body-weight supported treadmill walking program compared to a program combining lumbar flexion exercise and usual treadmill walking.(60) Another study found no difference between the addition of either treadmill with body weight support or cycling in addition to a program combining shockwave diathermy, traction and home exercises.(61) Recently, Koc et al.(62) published a small controlled study including 33 patients ( 29 analyzed) who were randomized into 3 groups and evaluated after 6 months. All patients received diclofenac and training to perform twice daily stretching and strengthening home-exercises. In addition, one group received inpatient physical therapy (ultrasounds, hot packs and TENS) for 2 weeks and another received epidural steroid injections. The authors reported that both physical therapy and epidural injection were effective, but no statistical difference was found at 6 months compared to those who received only medication and training (control group). The only significant difference was greater improvement at 2 weeks in pain and function in the epidural injection group compared to controls. A prospective cohort study involving 145 patients, evaluated a 4week intensive, inpatient, multimodal program (ultrasound, infrared heating, active therapy and subcutaneous salmon calcitonin).(63) At the end of the program, $91 \%$ were classified as pain free and the walking capacity improved in $89 \%$. In a smaller uncontrolled trial,(64) bracing was able to decrease pain and increase the walking distance as measured on a treadmill.

\section{Epidural injections}

LSS account for $30 \%$ of all epidural injection.(26) Systematic reviews of epidural injections are often confusing as they generally mix different spine syndromes (radiculopathy, LSS, failed-back, discogenic back pain, etc.), different techniques (use of fluoroscopy; interlaminar, caudal or transforaminal (peri-radicular) injection route), or both.(65-68) In general, results of epidural corticosteroids for LSS have shown limited benefit. Parr et al, reviewed the evidence on interlaminar epidural injections, none of which used fluoroscopic guidance.(69) Two randomized trials $(70,71)$ and one blinded observational study(72) met eligibility criteria for lumbar spinal stenosis, and none showed positive short or long-term benefit on pain. A more recent, small RCT using fluoroscopic guidance and a control group that did not receive a placebo injection found a short term ( 2 weeks) effect of one interlaminar epidural corticosteroids injection on both pain and function when administered in addition to oral diclofenac and twice daily stretching and strengthening home exercises.(62)

A review by Conn et al.(73) focused on caudal epidural injections, and included one randomized controlled trial,(74) 2 prospective cohort studies, $(75,76)$ and 1 retrospective cohort study(77) involving patients with LSS. All studies showed favorable short ( $<6$ months) and long term (1 year) relief of pain (defined as at least 50\% reduction). However, the RCT did not include a placebo group and found no difference between bupivacaine and corticosteroids.(74)

For monoradicular pain, a single RCT found that foraminal infiltration of corticosteroids and bupivacaine produced similar effect compared to bupivacaine alone (included patients with 
disc herniation or degenerative stenosis).(78) At 3 months, the reduction in Oswestry Disability Index was significantly superior in patients with disc herniation compared to patients with degenerative stenosis. Similar findings were observed in a previous cohort study.(79)

\section{Surgery}

A number of different surgical techniques are used to treat patients with LSS and persistent symptoms that have not been adequately controlled by other therapeutic modalities. The most common procedure involves a decompressive laminectomy of the structures thought to be causing nerve root irritation. However, other procedures are also available, but their long-term safety and effectiveness compared to decompressive laminectomy remains to be established. For patients thought to have multilevel symptomatic LSS, some physicians recommend decompressive laminectomy with fusion due to concerns about causing "spinal instability". However, studies have not adequately defined which patients would potentially benefit from these more complicated procedures and this may be one factor accounting for wide variations in their use across geographic regions.(6)

Decompressive Laminectomy-Several meta-analyses on degenerative spinal spondylosis have been published.(80,81) The long term success rates of surgery vary between 45 and $72 \%$, depending on the endpoint (ability to work, neurologic symptoms, leg/back pain). Most of these reviews addressed the broad perspective of surgical interventions for degenerative changes in general and only one manuscript focused on LSS studies.(81) More recently, two high quality randomized controlled trial have compared surgery with conservative treatments for patients with LSS. In the first study,(82) 94 patients were randomized to laminectomy or structured conservative treatments (information, NSAIDs, individually structured programs which included trunk muscle endurance and stretching-type exercises, education on pain-relieving body postures and basic ergonomics related to lifting and carrying). Surgery was found more effective on pain and function at 1 and 2 years. No effect was observed on walking capacities.

The second study, which was part of the SPORT trials, combined a randomized control trial (289 patients) and an observational cohort study (365 patients) comparing laminectomy to "usual care" (with recommendation to include at least education, home exercises program, and NSAIDs if tolerated).(83) At 2 years, intention-to-treat analysis showed a small but significant improvement in bodily pain (a primary outcome subscale of the SF-36) in favor of surgery. No effect was observed in term of function (physical function from SF-36 or the Oswestry disability index). Combining both cohorts, the as-treated analysis showed that treatment effects were significant in favor of surgery for all primary and secondary outcome measures at each time point during the 2 years. This study was notable because of the high rate of non-adherence to treatment allocation for both treatment groups (at 2 years, $63 \%$ of the patients allocated to surgery had received an operation compared to $43 \%$ in the control group). The reported astreated analysis is comparable to a well designed cohort study and the SPORT results are similar to a previously published cohort study.(49) The result is that the intention-to-treat analyses likely underestimates the relative benefit of surgery and the as-treated analyses may overstate it.

Comparing 3 different surgical approaches in patient with neurogenic claudication due to central stenosis, Thomé et. al.(84) randomized 120 patients between bilateral laminotomy, unilateral laminotomy or laminectomy. Bilateral laminotomy was superior to the other treatments in terms of back and leg pain both at rest and while walking. Walking distance improved in all 3 groups, but no between group differences were observed. 
Other surgical procedures-A multicentre randomized controlled trial involving 191 patients with one or two level spinal stenosis compared the placement of X Stop® interspinous decompression system to conservative care (all patients had at least one epidural injection and then had potential access to education, exercises, analgesics, NSAIDs and bracing). At 1 year, better scores on a validated disease specific functional questionnaire were observed in the surgical group.(85) The effect on function and quality of life was maintained at 2 years.(86, 87)

\section{Surgical Complications and Predictors of Outcomes}

Few large studies have reported complication rates associated with surgery for LSS. In the SPORT trial, serious surgical complications and death were very rare.(80) However, rates of serious complications have been shown to be associated with increasing age and comorbidity as well as for surgery that involves fusion(5).

The improvement in quality of life of patients after 1 or 2 level decompressive surgery for LSS is similar to patients undergoing knee replacement for osteoarthritis.(4) However, both groups have significantly less improvement than patients undergoing hip replacement for osteoarthritis. A review of 21 studies on predictors of improvement after surgery for LSS, (88) found that depression, cardiovascular comorbidities, disorder influencing walking ability, and scoliosis predicted poorer subjective outcomes. Better walking ability, self-rated health, higher income, less overall comorbidities, and pronounced central stenosis predicted better subjective outcome.

\section{Rehabilitation program after surgery}

In a randomized controlled trial, the addition of a structured rehabilitation program (stabilization exercises, 30 minutes twice a week for 12 weeks) started 2 months after decompressive surgery was not found to be superior to the simple recommendation to "stay active".(89)

\section{The Role for Shared Decision Making}

Because patients with LSS may have potentially unrealistic expectations about the risks and benefits of surgery,(90) it is recommended that decisions regarding surgery for LSS should be based on a shared decision making approach.(91) Shared decision making involves providing patients with the knowledge needed to make an informed decision and ensuring that the decision reflects the patient's preferences and values in terms of what matters most to the patient, e.g. pain relief, improved function, avoiding risk, etc. For patients with LSS, key knowledge would include the moderate benefit associated with surgery that may diminish over time, the likelihood of improvement with or without surgery, potential risk and costs.(91) Viewing a shared decision making program can improve the patient's knowledge and influence treatment decisions regarding spine surgery.(92)

\section{Summary}

LSS is a complex clinical syndrome resulting from degenerative changes in the lumbar spine. The diagnosis can be challenging and requires careful assessment of the patients' symptoms and physical examination findings with correlation of imaging results when considering invasive therapies. Although evidence is increasingly guiding care decisions, especially for surgical studies, there is still considerable uncertainty about the value of most non-surgical treatment modalities. Many commonly used treatments have never been evaluated and available evidence frequently relies on single randomized trials or observational data. 


\section{Practice points}

- The clinical diagnosis of LSS is based upon a history of symptoms consistent with neurogenic claudication and a physical examination that is commonly normal but can rule out other etiologies. The use of MRI is required to rule out other serious etiologies or when invasive procedures are being considered.

- Conservative therapies, activity modification, medications and physical treatments, are appropriate for first line management of symptomatic patients.

- When symptoms are not controlled with conservative therapies, a steroid injection (caudal or intralaminar with fluoroscopic guidance) should be considered.

- For patients with persistent severe pain and disabling functional impairment, a shared decision making process should be used to address the possible role of surgical intervention.

\section{Research Agenda}

- Designing and validating a set of classification criteria for LSS within a multicentre, multidisciplinary, international framework.

- Increase the understanding of the pathophysiology of pain in neurogenic claudication and better defining the role of inflammation and specific inflammatory mediators involved in this condition.

- Identify the key clinical features that differentiate patients with central, lateral and foraminal stenosis and their various combinations in order to design focused interventions.

- More multicenter randomized controlled studies investigating commonly used surgical and non-surgical treatments are required.

\section{References}

1. Verbiest $\mathrm{H}$. A radicular syndrome from developmental narrowing of the lumbar vertebral canal. J Bone Joint Surg Br 1954 May;36-B(2):230-7. [PubMed: 13163105]

2. Sachs B, Frankel V. Progressive and kyphotic rigidity of the spine. J Nerv Ment Dis 1900;27:1.

3. Genevay S, Atlas SJ, Katz JN. Variation in eligibility criteria from studies of radiculopathy due to a herniated disc and of neurogenic claudication due to lumbar spinal stenosis: A structured literature review. Spine. in press.

4. Rampersaud YR, Ravi B, Lewis SJ, Stas V, Barron R, Davey R, et al. Assessment of health-related quality of life after surgical treatment of focal symptomatic spinal stenosis compared with osteoarthritis of the hip or knee. Spine J 2008 Mar-Apr;8(2):296-304. [PubMed: 17669690]

5. Ciol MA, Deyo RA, Howell E, Kreif S. An assessment of surgery for spinal stenosis: time trends, geographic variations, complications, and reoperations. J Am Geriatr Soc 1996 Mar;44(3):285-90. [PubMed: 8600197]

6. Deyo RA, Gray DT, Kreuter W, Mirza S, Martin BI. United States trends in lumbar fusion surgery for degenerative conditions. Spine 2005 Jun 15;30(12):1441-5. discussion 6-7. [PubMed: 15959375]

7. Ciricillo SF, Weinstein PR. Lumbar spinal stenosis. West J Med 1993 Feb;158(2):171-7. [PubMed: 8434469]

8. Amundsen T, Weber H, Lilleas F, Nordal HJ, Abdelnoor M, Magnaes B. Lumbar spinal stenosis. Clinical and radiologic features. Spine 1995 May 15;20(10):1178-86. [PubMed: 7638662]

9. Johnsson KE, Rosen I, Uden A. The natural course of lumbar spinal stenosis. Clin Orthop Relat Res 1992 Jun;279:82-6. [PubMed: 1534726] 
10. Herno, A. Spinal Stenosis without deformity: Nonoperative treatment. In: Herkowitz, HH.; Dvorak, JJ.; Bell, G.; Nordin, M.; Grob, DD., editors. The Lumbar Spine. Philadelphia: Lippincott Williams \& Wilkins; 2004. p. 490-4.

11. Sairyo K, Biyani A, Goel V, Leaman D, Booth R Jr, Thomas J, et al. Pathomechanism of ligamentum flavum hypertrophy: a multidisciplinary investigation based on clinical, biomechanical, histologic, and biologic assessments. Spine 2005 Dec 1;30(23):2649-56. [PubMed: 16319751]

12. Jenis LG, An HS. Spine update. Lumbar foraminal stenosis. Spine 2000;25(3):389-94. [PubMed: 10703115]

13. Schönström N, Lindahl S, Willén J, Hansson T. Dynamic changes in the dimensions of the lumbar spinal canal: an experimental study in vitro. Journal of orthopaedic research 1989;7(1):115-21. [PubMed: 2908901]

14. Inufusa A, An HS, Lim TH, Hasegawa T, Haughton VM, Nowicki BH. Anatomic changes of the spinal canal and intervertebral foramen associated with flexion-extension movement. Spine 1996 Nov 1;21(21):2412-20. [PubMed: 8923625]

15. Porter RW, Ward D. Cauda equina dysfunction. The significance of two-level pathology. Spine 1992;17(1):9-15. [PubMed: 1536018]

16. Olmarker K, Rydevik B, Hansson T, Holm S. Compression-induced changes of the nutritional supply to the porcine cauda equina. J Spinal Disord 1990 Mar;3(1):25-9. [PubMed: 2134408]

17. Jespersen SM, Hansen ES, Høy K, Christensen KO, Lindblad BE, Ahrensberg JJ, et al. Two-level spinal stenosis in minipigs. Hemodynamic effects of exercise. Spine 1995;20(24):2765-73. [PubMed: 8747257]

18. Mao GP, Konno S, Arai I, Olmarker KK, Kikuchi SS. Chronic double-level cauda equina compression. An experimental study on the dog cauda equina with analyses of nerve conduction velocity. Spine 1998;23(15):1641-4. [PubMed: 9704369]

19. Olmarker K, Holm S, Rydevik B. Importance of compression onset rate for the degree of impairment of impulse propagation in experimental compression injury of the porcine cauda equina. Spine 1990 May;15(5):416-9. [PubMed: 2163547]

20. Cooke TD, Lehmann PO. Intermittent claudication of neurogenic origin. Canadian journal of surgery 1968;11(2):151-9.

21. Hanai K, Kawai K, Itoh Y, Satake T, Fujiyoshi F, Abematsu N. Simultaneous measurement of intraosseous and cerebrospinal fluid pressures in lumbar region. Spine 1985;10(1):64-8. [PubMed: 3983703]

22. Brish A, Lerner MA, Braham J. Intermittent claudication from compression of cauda equina by a narrowed spinal canal. J Neurosurgery 1964;21:207-11.

23. Takahashi K, Miyazaki T, Takino T, Matsui T, Tomita K. Epidural pressure measurements. Relationship between epidural pressure and posture in patients with lumbar spinal stenosis. Spine 1995 Mar 15;20(6):650-3. [PubMed: 7604339]

24. Morishita Y, Hida S, Naito M, Arimizu J, Matsushima U, Nakamura A. Measurement of the local pressure of the intervertebral foramen and the electrophysiologic values of the spinal nerve roots in the vertebral foramen. Spine 2006 Dec 15;31(26):3076-80. [PubMed: 17173006]

25. Chou R, Atlas SJ, Stanos SP, Rosenquist RW. Nonsurgical interventional therapies for low back pain: a review of the evidence for an american pain society clinical practice guideline. Spine 2009 May 1;34(10):1078-93. [PubMed: 19363456]

26. Friedly J, Chan L, Deyo R. Increases in lumbosacral injections in the Medicare population: 1994 to 2001. Spine 2007 Jul 15;32(16):1754-60. [PubMed: 17632396]

27. Igarashi A, Kikuchi S, Konno S. Correlation between inflammatory cytokines released from the lumbar facet joint tissue and symptoms in degenerative lumbar spinal disorders. J Orthop Sci 2007 Mar;12(2):154-60. [PubMed: 17393271]

28. Matsumoto M, Watanabe K, Tsuji T, Ishii K, Takaishi H, Nakamura M, et al. Nocturnal leg cramps: a common complaint in patients with lumbar spinal canal stenosis. Spine 2009 Mar 1;34(5):E18994. [PubMed: 19247159]

29. Inui Y, Doita M, Ouchi K, Tsukuda M, Fujita N, Kurosaka M. Clinical and radiologic features of lumbar spinal stenosis and disc herniation with neuropathic bladder. Spine 2004 Apr 15;29(8):86973. [PubMed: 15082986] 
30. Bridwell KH. Lumbar spinal stenosis. Diagnosis, management, and treatment. Clin Geriatr Med 1994 Nov;10(4):677-701. [PubMed: 7850697]

31. Johnsson KE, Rosen I, Uden A. The natural course of lumbar spinal stenosis. Acta Orthop Scand Suppl 1993;251:67-8. [PubMed: 8451991]

32. Turner JA, Ersek M, Herron L, Deyo R. Surgery for lumbar spinal stenosis. Attempted meta-analysis of the literature. Spine 1992 Jan;17(1):1-8. [PubMed: 1531550]

33. Hai, Y. Classification, Natural Histrory, and Clinical Evaluation. In: Herkowitz, HH.; Dvorak, JJ.; Bell, G.; Nordin, M.; Grob, DD., editors. The Lumbar Spine. Philadelphia: Lippincott Williams \& Wilkins; 2004. p. 464-71.

34. Arbit E, Pannullo S. Lumbar stenosis: a clinical review. Clin Orthop Relat Res 2001 Mar;384:13743. [PubMed: 11249158]

35. Katz JN, Dalgas M, Stucki GG, Katz NP, Bayley J, Fossel AH, et al. Degenerative lumbar spinal stenosis. Diagnostic value of the history and physical examination. Arthritis and rheumatism 1995;38 (9):1236-41. [PubMed: 7575718]

36. Konno S, Kikuchi S, Tanaka Y, Yamazaki K, Shimada Y, Takei H, et al. A diagnostic support tool for lumbar spinal stenosis: a self-administered, self-reported history questionnaire. BMC Musculoskelet Disord 2007;8:102. [PubMed: 17967201]

37. Konno S, Hayashino Y, Fukuhara S, Kikuchi S, Kaneda K, Seichi A, et al. Development of a clinical diagnosis support tool to identify patients with lumbar spinal stenosis. European spine journal 2007;16(11):1951-7. [PubMed: 17549525]

38. Jarvik JG, Deyo RA. Diagnostic evaluation of low back pain with emphasis on imaging. Ann Intern Med 2002 Oct 1;137(7):586-97. [PubMed: 12353946]

39. Verbiest H. Pathomorphologic aspects of developmental lumbar stenosis. Orthop Clin North Am 1975 Jan;6(1):177-96. [PubMed: 1113966]

40. Eisenstein $S$. The trefoil configuration of the lumbar vertebral canal. A study of South African skeletal material. J Bone Joint Surg Br 1980 Feb;62-B(1):73-7. [PubMed: 7351439]

41. Schonstrom NS, Bolender NF, Spengler DM. The pathomorphology of spinal stenosis as seen on CT scans of the lumbar spine. Spine 1985 Nov;10(9):806-11. [PubMed: 4089655]

42. Schonstrom N, Bolender NF, Spengler DM, Hansson TH. Pressure changes within the cauda equina following constriction of the dural sac. An in vitro experimental study. Spine 1984 Sep;9(6):604-7. [PubMed: 6495030]

43. Schonstrom N, Hansson T. Pressure changes following constriction of the cauda equina. An experimental study in situ. Spine 1988 Apr;13(4):385-8. [PubMed: 3406845]

44. Lohman CM, Tallroth K, Kettunen JA, Lindgren KA. Comparison of radiologic signs and clinical symptoms of spinal stenosis. Spine 2006 Jul 15;31(16):1834-40. [PubMed: 16845360]

45. Ogikubo O, Forsberg L, Hansson T. The relationship between the cross-sectional area of the cauda equina and the preoperative symptoms in central lumbar spinal stenosis. Spine 2007 Jun 1;32(13): 1423-8. discussion 9. [PubMed: 17545910]

46. Kent DL, Haynor DR, Larson EB, Deyo RA. Diagnosis of lumbar spinal stenosis in adults: a metaanalysis of the accuracy of CT, MR, and myelography. AJR Am J Roentgenol 1992 May;158 (5):1135-44. [PubMed: 1533084]

47. Haig AJ, Tong HC, Yamakawa KS, Quint DJ, Hoff JT, Chiodo A, et al. The sensitivity and specificity of electrodiagnostic testing for the clinical syndrome of lumbar spinal stenosis. Spine $2005 \mathrm{Dec} 1 ; 30$ (23):2667-76. [PubMed: 16319753]

48. Amundsen T, Weber H, Nordal HJ, Magnaes B, Abdelnoor M, Lilleâs F. Lumbar spinal stenosis: conservative or surgical management?: A prospective 10-year study. Spine 2000;25(11):1424-35. discussion 35. [PubMed: 10828926]

49. Atlas SJ, Keller RB, Wu YA, Deyo RA, Singer DE. Long-term outcomes of surgical and nonsurgical management of lumbar spinal stenosis: 8 to 10 year results from the maine lumbar spine study. Spine 2005;30(8):936-43. [PubMed: 15834339]

50. Watters WC 3rd, Bono CM, Gilbert TJ, Kreiner DS, Mazanec DJ, Shaffer WO, et al. An evidencebased clinical guideline for the diagnosis and treatment of degenerative lumbar spondylolisthesis. Spine J. 2009 May 15; 
51. Chou R, Qaseem A, Snow V, Casey D, Cross JT Jr, Shekelle P, et al. Diagnosis and treatment of low back pain: a joint clinical practice guideline from the American College of Physicians and the American Pain Society. Ann Intern Med 2007 Oct 2;147(7):478-91. [PubMed: 17909209]

52. Eskola A, Pohjolainen T, Alaranta H, Soini J, Tallroth K, Slatis P. Calcitonin treatment in lumbar spinal stenosis: a randomized, placebo-controlled, double-blind, cross-over study with one-year follow-up. Calcif Tissue Int 1992 May;50(5):400-3. [PubMed: 1596776]

53. Podichetty VK, Segal AM, Lieber M, Mazanec DJ. Effectiveness of salmon calcitonin nasal spray in the treatment of lumbar canal stenosis: a double-blind, randomized, placebo-controlled, parallel group trial. Spine 2004 Nov 1;29(21):2343-9. [PubMed: 15507793]

54. Tafazal SI, Ng L, Sell P. Randomised placebo-controlled trial on the effectiveness of nasal salmon calcitonin in the treatment of lumbar spinal stenosis. Eur Spine J 2007 Feb;16(2):207-12. [PubMed: 16865379]

55. Yaksi A, Ozgönenel L, Ozgönenel B. The efficiency of gabapentin therapy in patients with lumbar spinal stenosis. Spine 2007;32(9):939-42. [PubMed: 17450066]

56. Matsudaira K, Seichi A, Kunogi J, Yamazaki T, Kobayashi A, Anamizu Y, et al. The efficacy of prostaglandin E1 derivative in patients with lumbar spinal stenosis. Spine 2009 Jan 15;34(2):11520. [PubMed: 19112336]

57. Rittenberg JD, Ross AE. Functional rehabilitation for degenerative lumbar spinal stenosis. Phys Med Rehabil Clin N Am 2003 Feb;14(1):111-20. [PubMed: 12622486]

58. Vo AN, Kamen LB, Shih VC, Bitar AA, Stitik TP, Kaplan RJ. Rehabilitation of orthopedic and rheumatologic disorders. 5. Lumbar spinal stenosis. Arch Phys Med Rehabil 2005 Mar;86(3 Suppl 1):S69-76. [PubMed: 15761804]

59. Whitman JM, Flynn TW, Fritz JM. Nonsurgical management of patients with lumbar spinal stenosis: a literature review and a case series of three patients managed with physical therapy. Phys Med Rehabil Clin N Am 2003 Feb;14(1):77-101. vi-vii. [PubMed: 12622484]

60. Whitman JM, Flynn TW, Childs JD, Wainner RS, Gill HE, Ryder MG, et al. A comparison between two physical therapy treatment programs for patients with lumbar spinal stenosis: a randomized clinical trial. Spine 2006 Oct 15;31(22):2541-9. [PubMed: 17047542]

61. Pua YH, Cai CC, Lim KC. Treadmill walking with body weight support is no more effective than cycling when added to an exercise program for lumbar spinal stenosis: a randomised controlled trial. The Australian journal of physiotherapy 2007;53(2):83-9. [PubMed: 17535143]

62. Koc Z, Ozcakir S, Sivrioglu K, Gurbet A, Kucukoglu S. Effectiveness of physical therapy and epidural steroid injections in lumbar spinal stenosis. Spine 2009 May 1;34(10):985-9. [PubMed: 19404172]

63. Onel D, Sari H, Donmez C. Lumbar spinal stenosis: clinical/radiologic therapeutic evaluation in 145 patients. Conservative treatment or surgical intervention? Spine 1993 Feb;18(2):291-8. [PubMed: 8441947]

64. Prateepavanich P, Thanapipatsiri S, Santisatisakul P, Somshevita P, Charoensak T. The effectiveness of lumbosacral corset in symptomatic degenerative lumbar spinal stenosis. J Med Assoc Thai 2001 Apr;84(4):572-6. [PubMed: 11460971]

65. Airaksinen O, Brox JI, Cedraschi C, Hildebrandt J, Klaber-Moffett J, Kovacs F, et al. Chapter 4. European guidelines for the management of chronic nonspecific low back pain. Eur Spine J 2006 Mar;15( Suppl 2):S192-300. [PubMed: 16550448]

66. Nelemans PJ, deBie RA, deVet HC, Sturmans F. Injection therapy for subacute and chronic benign low back pain. Spine 2001 Mar 1;26(5):501-15. [PubMed: 11242378]

67. van Tulder MW, Koes BW, Bouter LM. Conservative treatment of acute and chronic nonspecific low back pain. A systematic review of randomized controlled trials of the most common interventions. Spine 1997 Sep 15;22(18):2128-56. [PubMed: 9322325]

68. Watts RW, Silagy CA. A meta-analysis on the efficacy of epidural corticosteroids in the treatment of sciatica. Anaesth Intensive Care 1995 Oct;23(5):564-9. [PubMed: 8787255]

69. Parr AT, Diwan S, Abdi S. Lumbar interlaminar epidural injections in managing chronic low back and lower extremity pain: a systematic review. Pain Physician 2009 Jan-Feb;12(1):163-88.

[PubMed: 19165302] 
70. Cuckler JM, Bernini PA, Wiesel SW, Booth RE Jr, Rothman RH, Pickens GT. The use of epidural steroids in the treatment of lumbar radicular pain. A prospective, randomized, double-blind study. $\mathrm{J}$ Bone Joint Surg Am 1985 Jan;67(1):63-6. [PubMed: 3155742]

71. Wilson-MacDonald J, Burt G, Griffin D, Glynn C. Epidural steroid injection for nerve root compression. A randomised, controlled trial. J Bone Joint Surg Br 2005 Mar;87(3):352-5. [PubMed: 15773645]

72. Campbell MJ, Carreon LY, Glassman SD, McGinnis MD, Elmlinger BS. Correlation of spinal canal dimensions to efficacy of epidural steroid injection in spinal stenosis. J Spinal Disord Tech 2007 Apr;20(2):168-71. [PubMed: 17414988]

73. Conn A, Buenaventura RM, Datta S, Abdi S, Diwan S. Systematic review of caudal epidural injections in the management of chronic low back pain. Pain Physician 2009 Jan-Feb;12(1):109-35. [PubMed: 19165299]

74. Manchikanti L, Cash KA, McManus CD, Pampati VV, Abdi SS. Preliminary results of a randomized, equivalence trial of fluoroscopic caudal epidural injections in managing chronic low back pain: Part 4--Spinal stenosis. Pain physician 2008;11(6):833-48. [PubMed: 19057629]

75. Botwin K, Brown LA, Fishman M, Rao S. Fluoroscopically guided caudal epidural steroid injections in degenerative lumbar spine stenosis. Pain Physician 2007 Jul;10(4):547-58. [PubMed: 17660853]

76. Ciocon JO, Galindo-Ciocon D, Amaranath L, Galindo D. Caudal epidural blocks for elderly patients with lumbar canal stenosis. J Am Geriatr Soc 1994 Jun;42(6):593-6. [PubMed: 8201143]

77. Barre L, Lutz GE, Southern D, Cooper G. Fluoroscopically guided caudal epidural steroid injections for lumbar spinal stenosis: a restrospective evaluation of long term efficacy. Pain Physician 2004 Apr;7(2):187-93. [PubMed: 16868591]

78. Sell P, Chaudhary N, Ng L. The efficacy of corticosteroids in periradicular infiltration for chronic radicular pain: a randomized, double-blind, controlled trial. Spine 2005;30(8):857-62. [PubMed: 15834326]

79. Ng LC, Sell P. Outcomes of a prospective cohort study on peri-radicular infiltration for radicular pain in patients with lumbar disc herniation and spinal stenosis. Eur Spine J 2004 Jul;13(4):325-9. [PubMed: 14714243]

80. Gibson JN, Waddell G. Surgery for degenerative lumbar spondylosis. The Cochrane database of systematic reviews 2005;(4):CD001352.

81. Niggemeyer O, Strauss JM, Schulitz KP. Comparison of surgical procedures for degenerative lumbar spinal stenosis: a meta-analysis of the literature from 1975 to 1995. European spine journal 1997;6 (6):423-9. [PubMed: 9455673]

82. Malmivaara A, Slatis P, Heliovaara M, Sainio P, Kinnunen H, Kankare J, et al. Surgical or nonoperative treatment for lumbar spinal stenosis? A randomized controlled trial. Spine 2007 Jan 1;32(1):1-8. [PubMed: 17202885]

83. Weinstein JN, Tosteson TD, Lurie JD, Tosteson AN, Blood E, Hanscom B, et al. Surgical versus nonsurgical therapy for lumbar spinal stenosis. New England Journal of Medicine 2008;358(8):794810. [PubMed: 18287602]

84. Thomé C, Zevgaridis D, Leheta O, Bäzner H, Pöckler-Schöniger C, Wöhrle J, et al. Outcome after less-invasive decompression of lumbar spinal stenosis: a randomized comparison of unilateral laminotomy, bilateral laminotomy, and laminectomy. Journal of neurosurgery Spine 2005;3(2):12941. [PubMed: 16370302]

85. Zucherman JF, Hsu KY, Hartjen CA, Mehalic TF, Implicito DA, Martin MJ, et al. A prospective randomized multi-center study for the treatment of lumbar spinal stenosis with the X STOP interspinous implant: 1-year results. Eur Spine J 2004 Feb;13(1):22-31. [PubMed: 14685830]

86. Zucherman JF, Hsu KY, Hartjen CA, Mehalic TF, Implicito DA, Martin MJ, et al. A multicenter, prospective, randomized trial evaluating the X STOP interspinous process decompression system for the treatment of neurogenic intermittent claudication: two-year follow-up results. Spine 2005 Jun 15;30(12):1351-8. [PubMed: 15959362]

87. Hsu KY, Zucherman JF, Hartjen CA, Mehalic TF, Implicito DA, Martin MJ, et al. Quality of life of lumbar stenosis-treated patients in whom the X STOP interspinous device was implanted. Journal of neurosurgery Spine 2006;5(6):500-7. [PubMed: 17176013] 
88. Aalto TJ, Malmivaara A, Kovacs F, Herno A, Alen M, Salmi L, et al. Preoperative predictors for postoperative clinical outcome in lumbar spinal stenosis: systematic review. Spine 2006;31 (18):E648-63. [PubMed: 16915081]

89. Mannion AF, Denzler R, Dvorak J, Müntener M, Grob D. A randomised controlled trial of postoperative rehabilitation after surgical decompression of the lumbar spine. European spine journal 2007;16(8):1101-17. [PubMed: 17593405]

90. Toyone T, Tanaka T, Kato D, Kaneyama R, Otsuka M. Patients' expectations and satisfaction in lumbar spine surgery. Spine 2005;30(23):2689-94. [PubMed: 16319756]

91. Chou R, Loeser JD, Owens DK, Rosenquist RW, Atlas SJ, Baisden J, et al. Interventional therapies, surgery, and interdisciplinary rehabilitation for low back pain: an evidence-based clinical practice guideline from the American Pain Society. Spine 2009 May 1;34(10):1066-77. [PubMed: 19363457]

92. Deyo RA, Cherkin DC, Weinstein J, Howe J, Ciol M, Mulley AG Jr. Involving patients in clinical decisions: impact of an interactive video program on use of back surgery. Med Care 2000 Sep;38(9): 959-69. [PubMed: 10982117] 


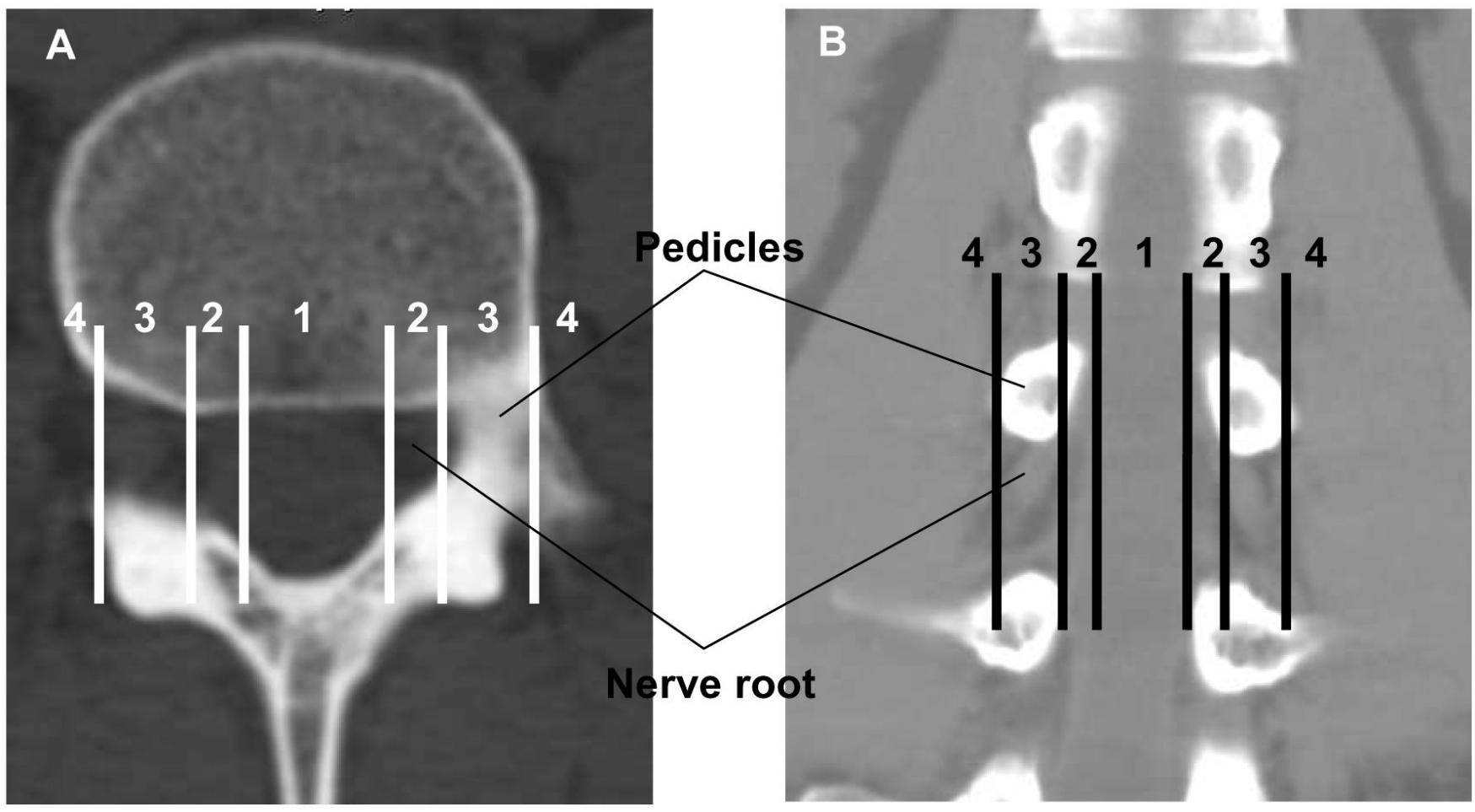

Figure 1.

Lumbar vertebrae. Potential regions of contact with nerve roots as described by Jenis(12): 1 central; 2 lateral recess; 3 foramen; 4 extraforaminal 
Table 1

Self-administered, self-reported history questionnaire to diagnose lumbar spinal stenosis and its clinical subtypes

\begin{tabular}{|l|l|}
\hline Q1 & Numbness and/or pain in the thighs down to the calves and shins. \\
\hline Q2 & Numbness and/or pain increase in intensity after walking for a while, but are relieved by taking a rest. \\
\hline Q3 & Standing for a while brings on numbness and/or pain in the thighs down to the calves and shins. \\
\hline Q4 & Numbness and/or pain are reduced by bending forward. \\
\hline & Key questions for diagnosis of cauda equina symptoms: \\
\hline Q5 & Numbness is present in both legs. \\
\hline Q6 & Numbness is present in the soles of both feet \\
\hline Q7 & Numbness arises around the buttocks. \\
\hline Q8 & Numbness is present, but pain is absent. \\
\hline Q) & A burning sensation arises around the buttocks. \\
\hline Q10 & Walking nearly causes urination. \\
\hline
\end{tabular}

According to the authors (36) a score of 4 points on Q1-Q4 indicates the presence of LSS; a score of 4 on Q1-Q4 and < 1 on Q5-Q10 indicates the radicular type of LSS and a score of > 1 on Q1-Q4 and > 2 on Q5-Q10 indicates the neurogenic claudication (referred as cauda equina in their manuscript) type of LSS. In the validation cohort, the questionnaire had a sensitivity of $84 \%$ and a specificity of $78 \%$ in diagnosing LSS. 
Table 2

A clinical diagnosis support tool to identify patients with lumbar spinal stenosis

\begin{tabular}{|l|c|}
\hline & Points \\
\hline Age: 60-70 70 & 1 \\
\hline Absence of diabetes & 1 \\
\hline Intermittent claudication & 3 \\
\hline Exacerbation of symptoms when standing up & 2 \\
\hline Symptom improvement when bending forward & 3 \\
\hline Symptoms induced by having patients bend forward & -1 \\
\hline Symptoms induced by having patients bend backward & 1 \\
\hline Good peripheral artery circulation & 3 \\
\hline Abnormal Achilles tendon reflex & 1 \\
\hline Straight leg raise test positive & -2 \\
\hline
\end{tabular}

The total score range from -2 to 16 . According to the authors (37), a score equal or greater than 7 has a sensitivity of $92.8 \%$ and a specificity of $72.0 \%$ for the diagnosis of symptomatic lumbar spinal stenosis 
Table 3

Summary of available evidence for treatments of symptomatic lumbar spinal stenosis

\begin{tabular}{|c|c|c|}
\hline Treatment & Comments & Level of evidence \\
\hline \multicolumn{3}{|l|}{ Drugs } \\
\hline Analgesic, NSAIDs, opioid, muscles relaxant & No study in LSS patients & - \\
\hline Gabapentin & Effect on pain and walking distance & Poor \\
\hline Limaprost (PGE1 derivative) & Effect on function & Poor \\
\hline Intranasal calcitonin & No effect & Fair \\
\hline Subcutaneous calcitonin & Effect on pain & Poor \\
\hline \multicolumn{3}{|l|}{ Physical therapy/Rehabilitation } \\
\hline $\begin{array}{l}\text { Combination therapy of manual physical therapy } \\
\text { interventions, exercise, and a progressive body- weight } \\
\text { supported treadmill walking }\end{array}$ & $\begin{array}{l}\text { Long term effect on perceived } \\
\text { recovery but not on pain or function }\end{array}$ & Poor \\
\hline Post surgery rehabilitation program & No effect & Fair \\
\hline \multicolumn{3}{|l|}{ Injection therapy } \\
\hline $\begin{array}{l}\text { Interlaminar epidural corticosteroids injection without } \\
\text { fluoroscopic guidance }\end{array}$ & No effect & Good \\
\hline $\begin{array}{l}\text { Interlaminar epidural corticosteroids injection with } \\
\text { fluoroscopic guidance }\end{array}$ & $\begin{array}{l}\text { Short term effect on pain and } \\
\text { function }\end{array}$ & Poor \\
\hline Caudal epidural injection & $\begin{array}{l}\text { Short and long term effect on pain } \\
\text { (reduction }>50 \%)\end{array}$ & Fair \\
\hline Addition of corticosteroids to bupivacaine & $\begin{array}{l}\text { Not superior to bupivacaine alone } \\
\text { on pain and function }\end{array}$ & Fair \\
\hline Foraminal injection & $\begin{array}{l}\text { Smaller benefit on function in } \\
\text { patient with LSS than with disc } \\
\text { herniation }\end{array}$ & Fair \\
\hline \multicolumn{3}{|l|}{ Surgery } \\
\hline Decompressive laminectomy & Better than "usual care" & Good \\
\hline $\mathrm{X}$-Stop ${ }^{\circledR}$ interspinous decompression & $\begin{array}{l}\text { Better than "usual care" on function } \\
\text { and quality of life }\end{array}$ & Fair \\
\hline Bilateral laminotomy & $\begin{array}{l}\text { Better than laminectomy and } \\
\text { unilateral laminotomy on pain }\end{array}$ & Fair \\
\hline
\end{tabular}

Level of evidence. Good = at least two consistent, higher-quality trials. Fair = at least one higher-quality trial of sufficient sample size; two or more higher-quality trials with some inconsistency; at least two consistent, lower-quality trials, or multiple consistent observational studies with no significant methodological flaws. Poor = Evidence is insufficient to assess effects on health outcomes because of limited number or power of studies, large and unexplained inconsistency between higher-quality trials, important flaws in trial design or conduct, gaps in the chain of evidence, or lack of information on important health outcomes 